\title{
Effect of Organic Solvent Extractives on Korean Softwoods Classification Using Near-infrared Spectroscopy ${ }^{1}$
}

\author{
Seungheon Yeon $^{2} \cdot$ Se-Yeong Park ${ }^{3}$ - Jong-Hwa $\mathrm{Kim}^{4} \cdot$ Jong-Chan $\mathrm{Kim}^{4} \cdot$ Sang-Yun Yang ${ }^{4}$ \\ Hwanmyeong $\mathrm{Yeo}^{4,6} \cdot$ Ohkyung $\mathrm{Kwon}^{5} \cdot$ In-Gyu Choi (iD) ${ }^{4,6,7, \dagger}$
}

\begin{abstract}
This study analyzed the effect of organic solvent extractives on the classification of wood species via near-infrared spectroscopy (NIR). In our previous research, five species of Korean softwood were classified into three groups (i.e., Cryptomeria japonica (cedar)/Chamaecyparis obtuse (cypress), Pinus densiflora (red pine)/Pinus koraiensis (Korean pine), and Larix kaempferi (Larch)) using an NIR-based principal component analysis method. Similar tendencies of extractive distribution were observed among the three groups in that study. Therefore, in this study, we qualitatively analyzed extractives extracted by an organic solvent and analyzed the NIR spectra in terms of the extractives' chemical structure and band assignment to determine their effect in more detail. Cedar/cypress showed a similar NIR spectra patterns by removing the extractives at 1695, 1724, and $2291 \mathrm{~nm}$. D-pinitol, which was detected in cedar, contributed to that wavelength. Red pine/Korean pine showed spectra changes at 1616, 1695, 1681, 1705, 1724, 1731, 1765, 1780, and $2300 \mathrm{~nm}$. Diterpenoids and fatty acid, which have a carboxylic group and an aliphatic double bond, contributed to that wavelength. Larch showed a catechin peak in gas chromatography and mass spectroscopy analysis, but it exhibited very small NIR spectra changes. The aromatic bond in larch seemed to have low sensitivity because of the 1st overtone of the O-H bond of the sawdust cellulose. The three groups sorted via NIR spectroscopy in the previous research showed quite different compositions of extractives, in accordance with the NIR band assignment. Thus, organic solvent extractives are expected to affect the classification of wood species using NIR spectroscopy.
\end{abstract}

Keywords: Near-infrared spectroscopy, classification in Korean softwood species, extractives, qualitative analysis, gas chromatography, thin layer chromatography

${ }^{1}$ Date Received April 29, 2019, Date Accepted July 15, 2019

2 Global R\&D Center, LG Household \& Healthcare, Seoul, 07795, Republic of Korea

${ }^{3}$ Department of Forest Biomaterials Engineering, College of Forest Environmental Sciences, Kangwon National University, Chuncheon, 24341, Republic of Korea

${ }^{4}$ Department of Forest Sciences, College of Agriculture and Life Sciences, Seoul National University, Seoul, 08826, Republic of Korea

${ }^{5}$ Nanobioimaging Center, National Instrumentation Center for Environmental Management, Seoul National University, Seoul, 08826, Republic of Korea

${ }^{6}$ Research Institute of Agriculture and Life Sciences, Seoul National University, Seoul, 08826, Republic of Korea

${ }^{7}$ Institutes of Green Bio Science and Technology, Seoul National University, Pyeongchang, 25354, Republic of Korea

† Corresponding author: In-Gyu Choi (e-mail: cingyu@snu.ac.kr, ORCID: 0000-0001-5604-6823) 
Seungheon Yeon • Se-Yeong Park • Jong-Hwa Kim • Jong-Chan Kim • Sang-Yun Yang •

Hwanmyeong Yeo $\cdot$ Ohkyung Kwon· In-Gyu Choi

\section{INTRODUCTION}

Wood is one of the most familiar materials to human and it has been used as useful resource in various fields such as architecture, paper industries and even as functional food ingredients (Jung et al., 2018). To utilize wood as valuable materials, understanding of the wood physical/chemical properties is important. Wood is mainly comprised of cellulose, hemicellulose, lignin and extractives, and they are linked one another by various chemical bondings such as hydrogen and carbon-carbon. These chemical structures lead to quite different properties of woods because content and composition of wood components varies depending on wood species (Sjostrom, 1993; Stark et al., 2003). Therefore, classification of wood species and understanding of its physical/chemical properties have been recognized as important factors and various technical analysis has been done for those purposes. However, classification of wood species, which have high similarity in appearance, is not easy for non-experts. In addition, traditional methods such as anatomical method and wet chemistry are difficult and labor-intensive work for wood classification. To solve these problems, near-infrared (NIR) spectroscopy has been applied recently. NIR spectroscopy measures light absorbance caused by wood's major components, it can be applied for rapid and nondestructive wood characterization (Kwon et al., 2017). Moreover, because each wood's major components have different patterns of absorbance, it can be possible to predict its chemical composition and species (Schwanninger et al., 2011).

In our previous researches, we evaluated the possibility of five species of Korean softwood classification using NIR spectroscopy. (Park et al., 2017; Yang et al., 2017). These researches described that five wood species (Cryptomeria japonica (cedar)/Chamaecyparis obtuse (cypress), Pinus densiflora (red pine)/Pinus koraiensis (Korean pine), Larix kaempferi (Larch)) were divided into three distinguishable groups; (Chamaecyparis obtuse/Cryptomeria japonica, Pinus densiflora/Pinus koraiensis, and Larix kaempferi). However, factors which sort five Korean softwoods into three groups were not figured out in detail and further researches were required.

In this study, organic solvent extractives were acquired from each three distinguishable groups using alcohol-benzene extraction method. Qualitative analysis of organic solvent extractives were conducted by using a gas chromatography, and thin layer chromatography method. Based on chemical information of the extractives, the interpretation of NIR spectra of each species was conducted at specific wavelength in order to figure out the relationship between the organic solvent extractives and NIR spectra for wood classification more clearly.

\section{MATERIALS and METHODS}

\subsection{Sample preparation}

For this study, five Korean softwoods, cedar (Cryptomeria japonica), cypress (Chamaecyparis obtuse), red pine (Pinus densiflora), Korean pine (Pinus koraiensis), and larch (Larix kaempferi), were purchased from the National Forestry Cooperative Federations in Republic of Korea. 50 rectangular lumber of each five softwood species was obtained (thickness $\times$ width $\times$ length $=50 \times 100 \times 600 \mathrm{~mm})$. To minimize deviation caused by direction of wood, each rectangular lumber was stranded five times at $2 \mathrm{~mm}$ interval. The stranded sawdust was ground and sieved at 40 mesh size. Totally, 1,250 wood powders (sawdust) were prepared for each species.

\subsection{Sample selection}

In previous research, among total 1250 ground samples of five softwoods, representative 150 samples 
(Red pine: 29, Korean pine: 41, Larch: 29, Cypress:25, Cedar: 26) were selected based on obtained NIR spectra, principle component analysis (PCA), and Mahalanobis distance theory. Sample selection of the representative samples was prepared according to the our previous research (Park et al., 2018). Additionally, the quantitative analysis of extractives of each selected sample was also conducted according to Technical Association of the Pulp and Paper Industry (TAPPI) ethanol-benzene (1:2, v/v) solution method (Sluiter et al., 2005).

To analyze the effect of extractives on NIR spectra more clearly, 3 samples for each species were selected depending on its extractives content (high, middle, and low) from the selected samples. The samples which had the highest and lowest content of extractives were selected as high and low extractives content samples. The samples which had extractives content close to average value were selected as middle extractives content samples.

\subsection{Acquisition of organic solvent extractives and extractives-removed sawdust}

For qualitative analysis and NIR spectra analysis, extractives of selected samples and extractives removed sawdust were required. To acquire extractives of selected samples (total 15 samples) and their extractivesremoved sawdust, alcohol-benzene $(1: 2, \mathrm{v} / \mathrm{v})$ solution method was used. $2 \mathrm{~g}$ of each sawdust was put into thimble filter (ADVANTEC, Japan) and extraction was conducted by TAPPI methods described in 2.2. After extraction, crude extract was evaporated and re-dissolved at $20 \mathrm{ml}$ of ethanol. The solid residue (extractivesremoved sawdust) of extraction was air-dried for $24 \mathrm{~h}$.

\subsection{Near-infrared (NIR) spectra measurement and spectra analysis}

NIR spectra of raw sawdust and extractives-removed sawdust were obtained using a SpectraStar 2600 XL instrument (Unity Scientific, Milord, MA, USA). Both raw sawdust and extractives-removed samples was put into a cup holder and light absorbance from 680 to $2600 \mathrm{~nm}$ wavelength was measured. OMNIC 9.2 software (Thermo Scientific, Waltham, MA, USA) was used as spectra analysis tool. To escape misinterpretation caused by overlapping of NIR absorbance peaks and analyze influence of extractives on NIR spectra more effectively, Savitsky-Golay $2^{\text {nd }}$ derivative pretreatment method was used (polynomial order: 3, smoothing point: 21) and the spectra were compared each other (Park et al., 2017).

\subsection{Qualitative analysis of organic solvent extractives of five Korean softwoods}

\subsubsection{Gas chromatography and mass spectroscopy analysis (GC/MS analysis)}

For qualitative analysis, GC/MS analysis for selected samples was conducted. To detect chemicals which are difficult to evaporate, trimethylsilylation reaction was carried out. Each $100 \mu \mathrm{l}$ of extractives samples were reacted with $100 \mu$ l of pyridine anhydrous and 100 $\mu$ Sylon BFT solution (BSTFA + TMCS (99:1), SUPELCO) at $105^{\circ} \mathrm{C}$ for $2 \mathrm{~h}$. After trimethylsilylation, the GC/MS analysis was carried out using Agilent DB-5 $(25 \mathrm{~m} \times 0.32 \mathrm{~mm} \times 0.52 \mu \mathrm{l})$ column and He gas as carrier gas. For detecting various kinds of wood extractives, oven temperature was set widely from $50^{\circ} \mathrm{C}$ to $300^{\circ} \mathrm{C}$ for $3^{\circ} \mathrm{C} / \mathrm{min}$ (Kim et al., 2017).

\subsubsection{Thin layer chromatography analysis (TLC analysis)}

To figure out similarity of extractives between each groups visually, the TLC method was conducted. The silica gel 60 plate was used as stationary phase and hexane-ethyl acetate $(2: 1, \mathrm{v} / \mathrm{v})$ solution was used as mobile phase. After the mobile phase moved com- 
Seungheon Yeon · Se-Yeong Park • Jong-Hwa Kim • Jong-Chan Kim • Sang-Yun Yang •

Hwanmyeong Yeo $\cdot$ Ohkyung Kwon· In-Gyu Choi

pletely, the images of extractives which were separated were acquired using ultraviolet light at 254 and 365 nm wavelength.

\section{RESULTS and DISCUSSION}

\subsection{Near-infrared (NIR) spectra change by extractives-removing}

Content and chemical structure of wood extractives could influence NIR spectra and it was observed in $2^{\text {nd }}$ derivative spectra of each wood species. Fig. 1 and Table 1 showed the $2^{\text {nd }}$ derivative NIR spectra change of red pine caused by removing extractives from raw sawdust samples and organic solvent extractives content of each sample. Except wavelength region which is influenced by water content, change of NIR spectra after removing extractives was observed especially at 1600 1800 nm and 2100 2500 nm. At Fig. 1, three samples have different extractives content, but they showed similar tendency of change at same wavelength. The amount of change increased in proportion to extractives content. High-extractives content sample (HE) showed the most bigger change and Lowextractives content sample (LE) showed mild change. From these results, it could be expected that content of organic solvent extractives and NIR spectra change had significant correlation.

Fig. 2 showed $2^{\text {nd }}$ derivative NIR spectra of raw sawdust and extractives-removed sawdust (high-extractives content sample of each wood species). All five species showed change of the $2^{\text {nd }}$ derivative NIR spectra. Cedar, cypress, and larch had relatively low extractives content and showed small spectra change compared to red pine and Korean pine (Table 1), but specific wavelength which the change was occurred were quite different depending on wood species. Cedar and cypress group showed spectra change at 1695, 1724, $2291 \mathrm{~nm}$. Red pine and Korean pine not only showed spectra change at 1695, 1724, $2291 \mathrm{~nm}$ which were observed at cedar and cypress group but also showed spectra change at 1616, 1681, 1705, 1731, 1765, and $1780 \mathrm{~nm}$ which were not observed at cedar and cypress. Larch showed almost no change in $2^{\text {nd }}$ derivative NIR spectra between raw sawdust and extractives-removed sample.

In previous researches, score plot of the five Korean gymnosperm samples by principal component analysis (PCA) showed three groups; cedar/cypress, red pine/ Korean pine, and larix. Similarly, the change of $2^{\text {nd }}$ derivative NIR spectra after removing extractives also showed same three groups which have high similarity

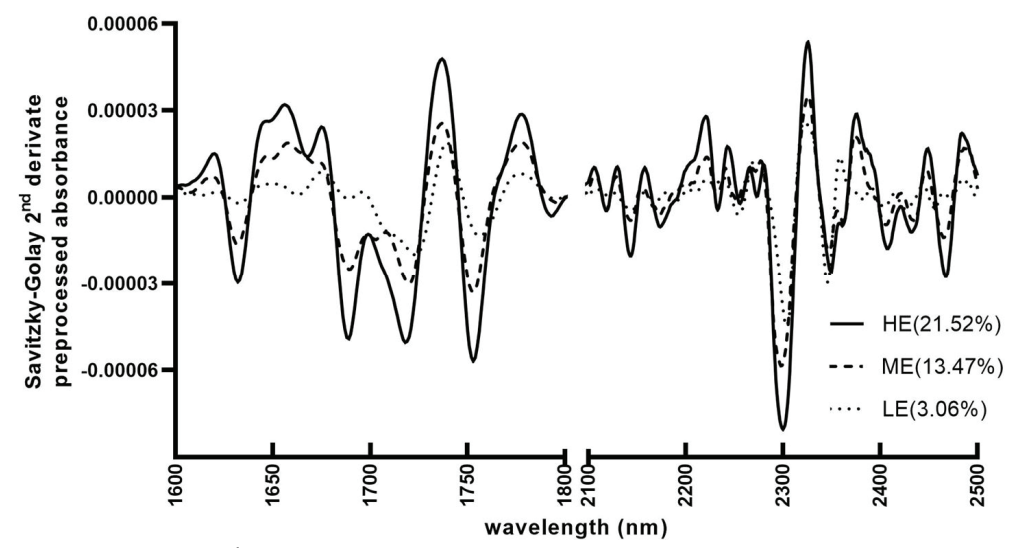

Fig. 1. Savitsky-Golay $2^{\text {nd }}$ derivative NIR spectra change of red pine after extractives-removing. 

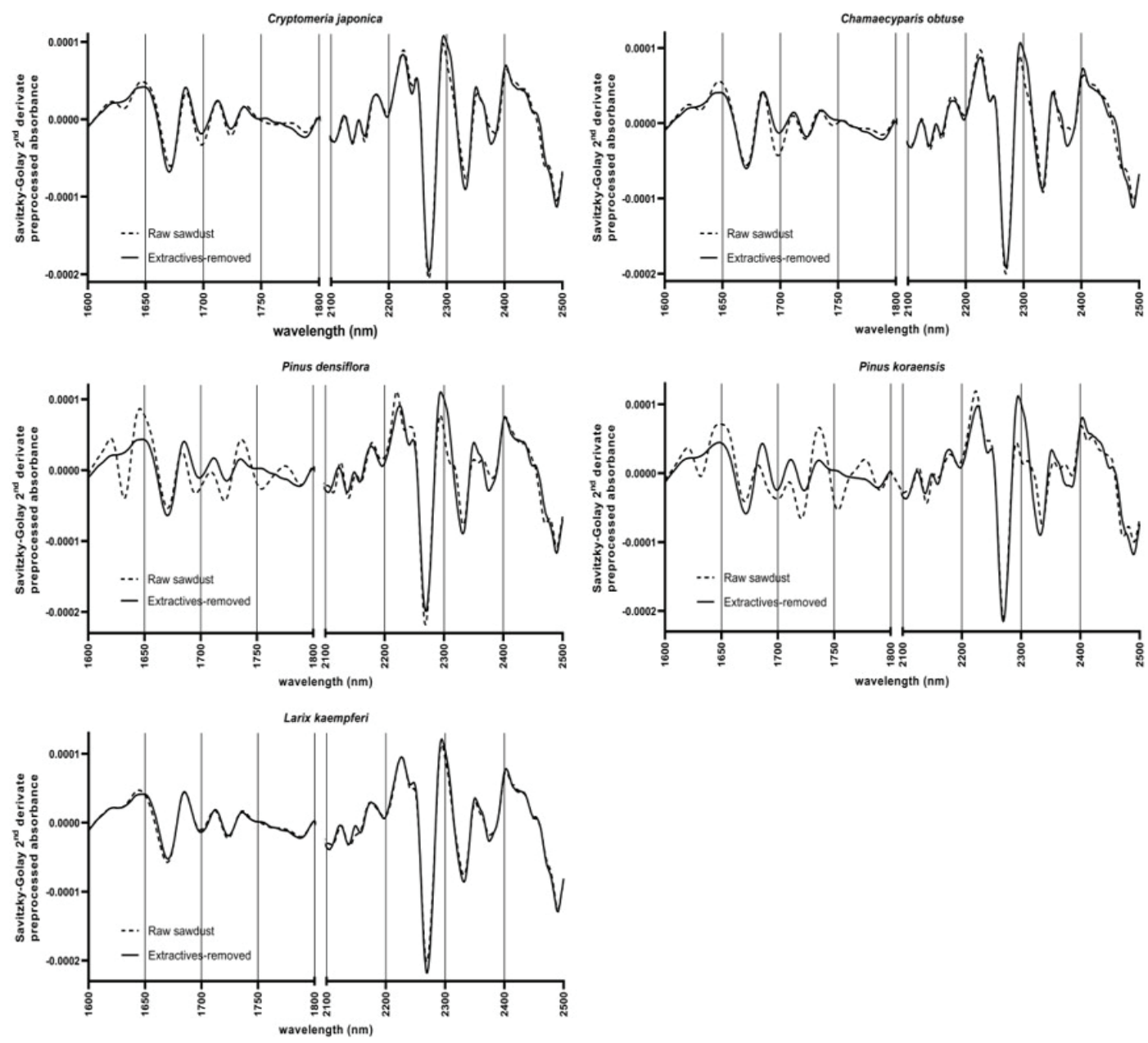

Fig. 2. Savitsky-Golay $2^{\text {nd }}$ derivative NIR spectra of raw sawdust and extractives-removed sample (HE).

Table 1. Organic solvent extractives content of five Korean softwoods samples

\begin{tabular}{cccc}
\hline $\begin{array}{c}\text { Wood } \\
\text { species }\end{array}$ & $\begin{array}{c}\text { High } \\
\text { Extractives } \\
\text { Content } \\
\text { Sample (\%) }\end{array}$ & $\begin{array}{c}\text { Mid } \\
\text { Extractives } \\
\text { Content } \\
\text { Sample (\%) }\end{array}$ & $\begin{array}{c}\text { Low } \\
\text { Extractives } \\
\text { Content } \\
\text { Sample (\%) }\end{array}$ \\
\hline \hline Cedar & 8.85 & 5.19 & 3.47 \\
Cypress & 7.16 & 3.55 & 2.47 \\
Red pine & 21.52 & 13.47 & 5.17 \\
Korean pine & 15.55 & 5.26 & 3.98 \\
Larch & 5.75 & 4.81 & 3.16 \\
\hline
\end{tabular}

in their NIR spectra change pattern (Chamaecyparis obtuse/Cryptomeria japonica, Pinus densiflora/Pinus koraiensis, Larix kaempferi) at specific wavelength. Therefore, it was expected that the organic solvent extractives of each wood species and their NIR spectra have significant correlation and extractives could be influence factor in wood classification using NIR spectroscopy. 
Seungheon Yeon · Se-Yeong Park · Jong-Hwa Kim • Jong-Chan Kim • Sang-Yun Yang •

Hwanmyeong Yeo $\cdot$ Ohkyung Kwon - In-Gyu Choi

\subsection{Qualitative analysis of organic solvent extractives and band assignment in NIR spectra}

Fig. 3 showed result of GC/MS analysis of five Korean softwood extractives (chemicals which have the highest probability). Crytomeria japonica (cedar) showed sharp and high intensity peak of D-pinitol around 50 55 min. Androstane and ferruginol were also detected around 60 65 min. Chamaecyparis obtuse (cypress) had eremophilene peak, but the signal was relatively weak. In this research, these extractives which were detected by GC/MS showed high consistency with band assignment of NIR spectra. At Fig. 2, cedar and cypress group showed NIR spectra change at 1695, 1724, $2291 \mathrm{~nm}$ by removing extractives. $1695 \mathrm{~nm}$ was assigned to $\mathrm{CH}_{3}$ groups (Schimleck and Evans, 2004) and $1724 \mathrm{~nm}$ was assigned to pyranose/furanose (Tsuchikawa, 2007). A band at $2291 \mathrm{~nm}$ was combination region of $\mathrm{C}-\mathrm{O}$ stretching/O-H stretching or $\mathrm{C}-\mathrm{H}_{2}$ bend/C- $\mathrm{H}_{2}$ stretching (Michell, 1996). Because D-pinitol has six $\mathrm{C}-\mathrm{H}$ groups, one $\mathrm{CH}_{3}$ groups, and five $\mathrm{O}-\mathrm{H}$ groups, it was expected D-pinitol could contribute to change of NIR spectra at 1695, 1724, $2291 \mathrm{~nm}$. Small amount of ferruginol which is kinds of diterpenoids also could contribute to change at that wavelength. D-pinitol and ferruginol did not have aliphatic double bond. Therefore, cedar and cypress did not show the change of NIR spectra at band assignment of double bond (such as $1616 \mathrm{~nm}$ ). In GC/MS analysis, cedar and cypress seemed to have no similarity, but TLC analysis images at Fig. 4 showed cedar and cypress had spots which were located at same position. It seemed that some extractives were not detected by GC/MS, but it was expected that extractives of cedar and cypress have some similarity in their structures.

Pinus densiflora (red pine) showed sharp and high intensity peaks of fatty acid and diterpenoids which have carboxylic groups and aliphatic double bonds.
Oleic acid was detected as fatty acid and pimaric acid, isopimaric acid, callitrisic acid, and abietic acid were detected as diterpenoids. Pinus Koraiensis (Korean pine) also showed sharp and high intensity peaks of diterpenoids such as isopimaric acid, callitrisic acid, abietic acid. Red pine and Korean pine showed high similarity in their extractives components in GC/MS analysis. The red pine and Korean pine group also showed high correlation between extractives and band assignment of NIR spectra. At Fig. 2, the $2^{\text {nd }}$ derivative spectra change of red pine and Korean pine groups showed different patterns with cedar and cypress group at 1616, 1681, 1705, 1731, 1765, and $1780 \mathrm{~nm} .1616$ nm was assigned to $=\mathrm{CH}_{2}$ groups (Baillères et al., 2002) and $1681 \mathrm{~nm}$ was assigned to acetyl, carboxylic, and carbonyl groups (Günzler et al., 1996). 1705, 1731, 1765 , and $1780 \mathrm{~nm}$ were assigned to $-\mathrm{CH}_{2}$ groups (Burns and Ciurczak, 2007; Weyer and Workman Jr, 2007). In GC/MS analysis (Fig. 3), fatty acid and diterpenoids which have carboxyl group, carbon-carbon double bond (not in cedar and cypress group) were detected at extractives of red pine and Korean pine. Oleic acid has one carboxyl group, one double bond, and fourteen $-\mathrm{CH}_{2}$ groups. Diterpenoids such as pimaric acid, callitrisic acid, abietic acid also have carboxyl group, much $-\mathrm{CH}_{2}$ groups, and double bond (except aromatic bond of callitrisic acid). These functional groups could contribute to change of NIR spectra at 1616, 1681, 1705, 1731, 1765, $1780 \mathrm{~nm}$ and made difference with cedar and cypress group. In addition, red pine and Korean pine showed relatively high amount of change in every wavelength because red pine and Korean pine had relatively higher extractives content than other species (cedar : 8.85\%, cypress : 7.16\%, red pine : 21.52\%, Korean pine : 15.47\%, larch : 6.15\%). In case of Larix kaempferi (larch), high and intensive catechin peak was detected and larch showed change of spectra at $1668 \mathrm{~nm}$ and $1674 \mathrm{~nm}$ which were referred to aromatic bond assignment (Barton et al., 1992). 
Effect of Organic Solvent Extractives on Korean Softwoods Classification Using Near-infrared Spectroscopy
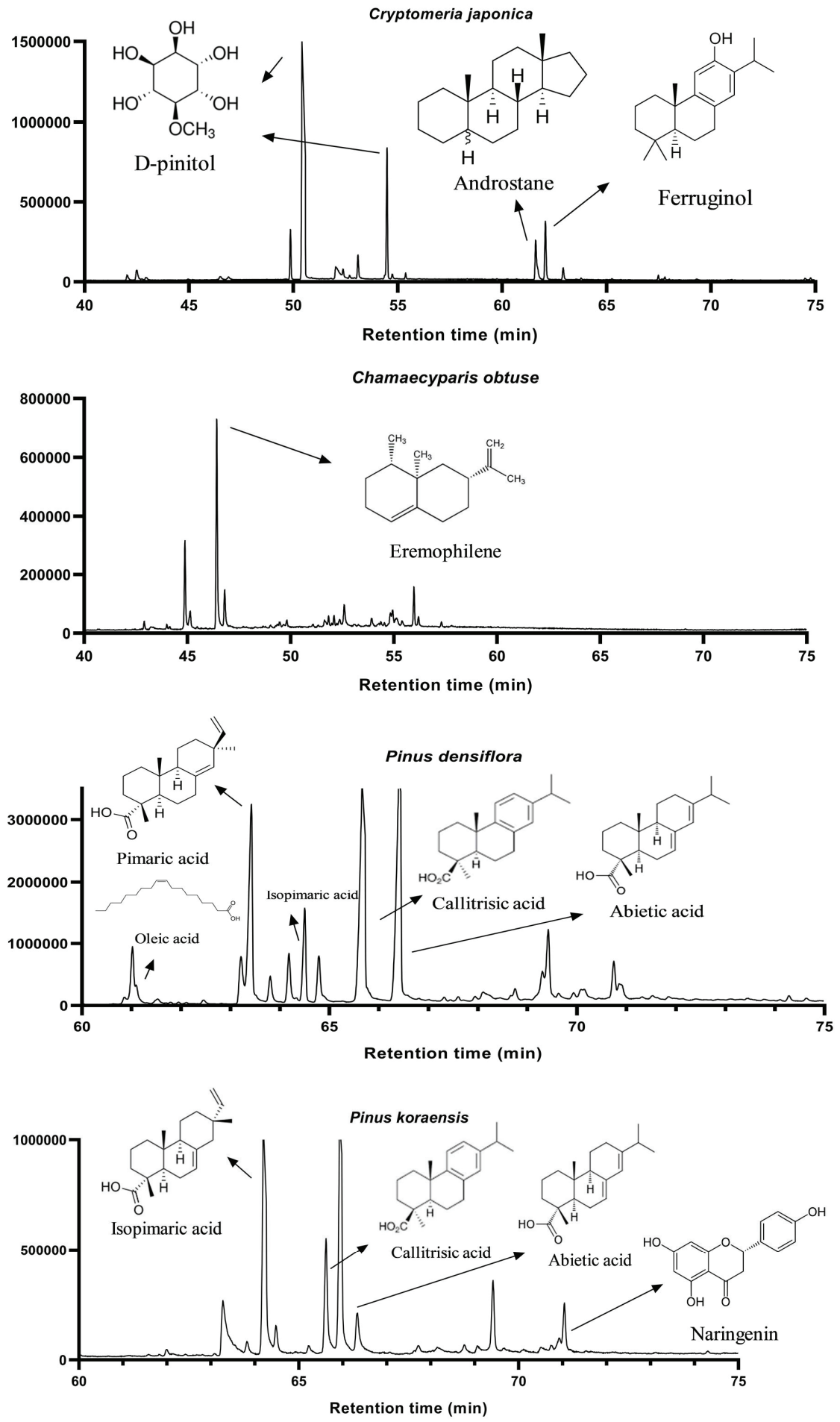
Seungheon Yeon · Se-Yeong Park • Jong-Hwa Kim • Jong-Chan Kim • Sang-Yun Yang • Hwanmyeong Yeo $\cdot$ Ohkyung Kwon - In-Gyu Choi

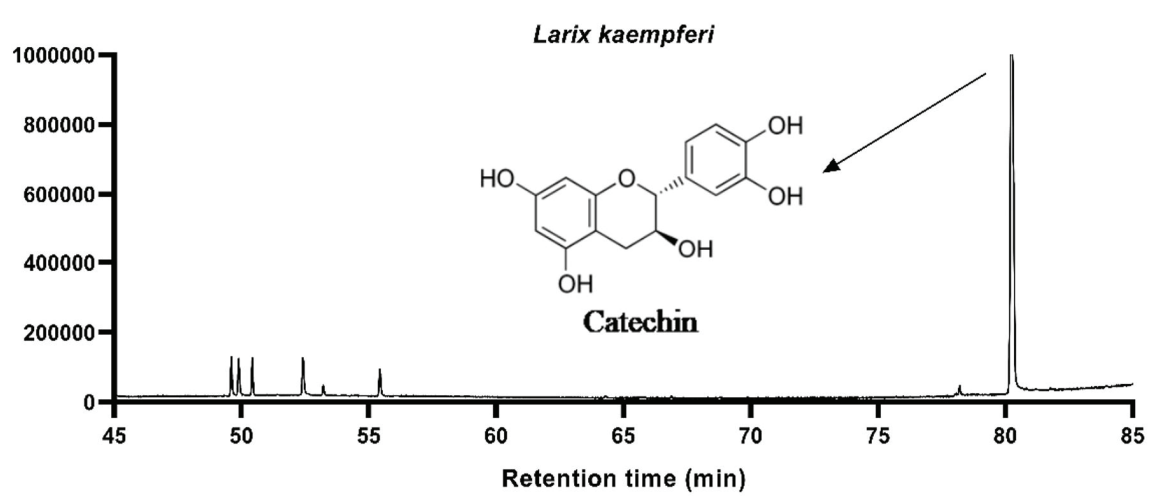

Fig. 3. Qualitative analysis of five Korean softwood extractives using GC/MS (HE samples).
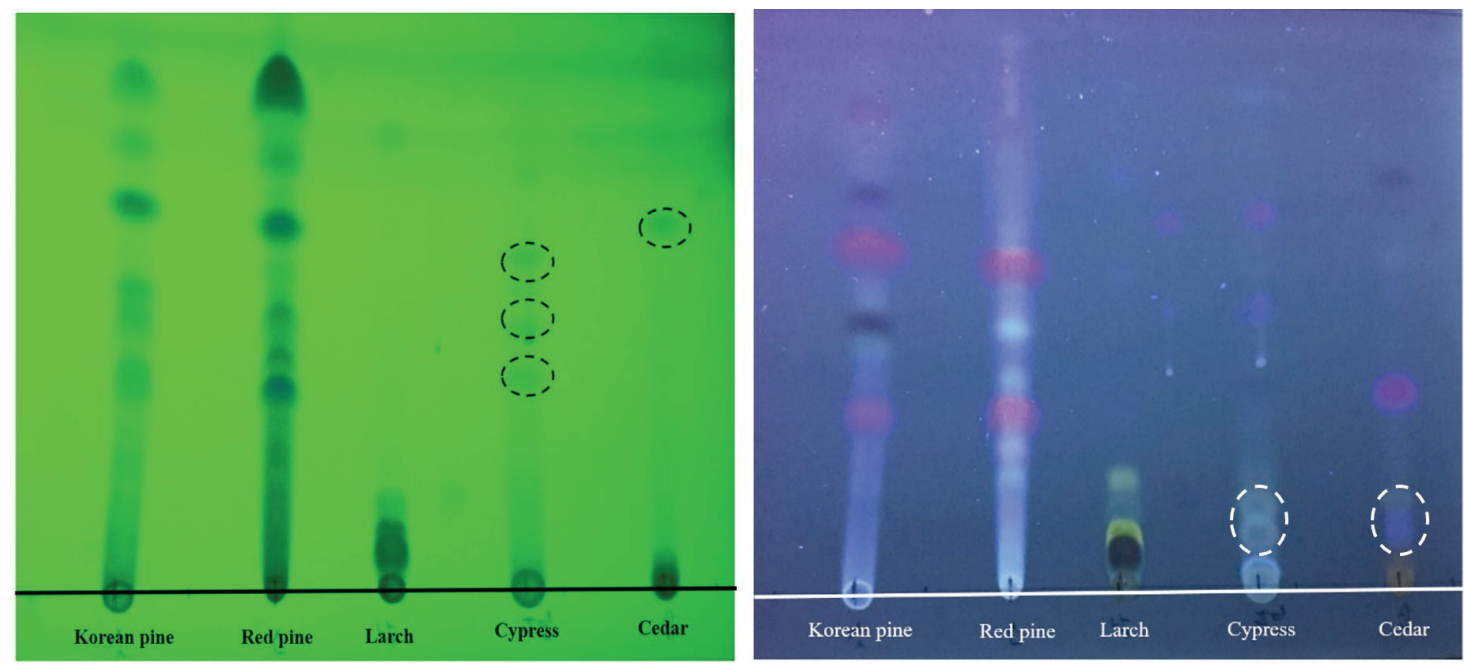

Fig. 4. Result of TLC analysis of five Korean softwood extractives (visualized at UV-254 (Left), 365nm (right)).

However, $2^{\text {nd }}$ derivative NIR spectra showed almost no change. It was expected that sensitivity of aromatic bond was very low in NIR region. Although the 1668 and $1674 \mathrm{~nm}$ are known as band assignment of aromatic C-H bond, this region is also affected by $1^{\text {st }}$ overtone of $\mathrm{O}-\mathrm{H}$ stretching. Therefore, in case of NIR measurement using sawdust, other major components of woods such as cellulose and hemi-cellulose could influence detection of aromatic extractives.

In TLC analysis (Fig. 4), red pine and Korean pine also showed almost same pattern and it meant that extractives of two pines have chemically similar structure. In the case of cedar and cypress, the similarity was not shown at $254 \mathrm{~nm}$, but similar two spots were observed at $365 \mathrm{~nm}$. The organic solvent extractives of larch showed quite different pattern with cedar/ cypress group and red pine/Korean pine. Extractives of larch had very low retention factor. It seemed that catechin which was detected at larch is relative polar extractives and mobile phase was quite non-polar solvent. 


\section{CONCLUSION}

This study analyzed the effect of organic solvent extractives on wood species classification using NIR spectroscopy. Extractives of each species were acquired by alcohol-benzene method and those extractives were analyzed using GC/MS and TLC method. NIR spectra of raw sawdust and extractives-removed sawdust were measured and NIR spectra was analyzed in terms of chemical structure of extractives and its band assignment.

Cedar/cypress showed NIR spectra change at similar wavelength and the change was seemed to be caused by extractives which had aliphatic $-\mathrm{CH},-\mathrm{CH}_{3}$ groups such as D-pinitol and ferruginol. However, Red pine/Korean pine showed quite different spectra change pattern with cedar/cypress. Fatty acids and diterpenoids which had carboxylic groups and double bonds were detected in extractives of both red pine and Korean pine. Because these extractives could influence aliphatic double bond and carbonyl group region, it was expected that red pine/Korean pine group showed different pattern with cedar/cypress group. Larch which had catechin as extractives showed only small change at NIR spectra. It was expected that aromatic bond had low sensitivity when the NIR measurement was conducted using wood sawdust because of other major components of woods. In this study, the factors which sort five Korean soft woods into three groups in previous researches were analyzed more detail in terms of extractives and its band assignment. The chemical structure of extractives influenced NIR spectra patterns. Therefore, it could be concluded that kinds of extractives as well as content of extractives could affect classification of Korean softwood species using NIR spectroscopy.

\section{ACKNOWLEDGMENT}

This study was carried out with the support of
'R\&D Program for Forest Science Technology (Project No. 2016009B10-1919-AB01)' provided by Korea Forest Service(Korea Forestry Promotion Institute).

\section{REFERENCES}

Baillères, H., Davrieux, F., Ham-Pichavant, F. 2002. Near infrared analysis as a tool for rapid screening of some major wood characteristics in a eucalyptus breeding program. Annals of Forest Science 59 (5-6): 479-490.

Barton, F.E., Himmelsbach, D.S., Duckworth, J.H., Smith, M.J. 1992. Two-dimensional vibration spectroscopy: correlation of mid-and near-infrared regions. Applied Spectroscopy 46(3): 420-429.

Burns, D.A., Ciurczak, E.W. 2001. Handbook of Nearinfrared Analysis. CRC press.

Günzler, H., Bahadir, A.M., Borsdorf, R., Danzer, K., Fresenius, W., Galensa, R., Huber, W., Lüderwald, I., Schwedt, G., Tölg, G., Wisser, H. 1996. Infrarotspektroskopie: Highlights aus dem AnalytikerTaschenbuch. Springer Berlin Heidelberg.

Hung, J.Y., Yang, J.K. 2018. A Two-stage Process for Increasing the Yield of Prebiotic-rich Extract from Pinus densiflora. Journal of the Korean Wood Science and Technology 46(4): 380-392.

Kim, S.H., Lee, S.Y., Cho, S.M., Hong, C.Y., Park, S.Y., Park, M.-J., Choi, I.G. 2017, Antioxidant activities of cryptomeria japonica leaves extracts by extraction methods. Journal of the Korean Wood Science and Technology 45(5): 495-510.

Kwon, O., Lee, H.G., Lee, M.R., Jang, S., Yang, S.Y.. Park, S.Y., Choi, I.G., Yeo, H. 2017. Automatic wood species identification of Korean softwood based on convolutional neural networks. Journal of the Korean Wood Science and Technology 45(6): 797-808.

Michell, A.J. 1996. NIR spectroscopy of woods from Eucalyptus globulus. Appita Journal 49: 23-26. 
Park, S.Y., Kim, J.C., Kim, J.H., Yang, S.Y., Kwon, O., Yeo, H., Cho, K.C., Choi, I.G. 2017. Possibility of wood classification in korean softwood species using near-infrared spectroscopy based on their chemical compositions. Journal of the Korean Wood Science and Technology 45(2): 202-212. Park, S.Y., Kim, J.C., Yeon, S., Yang, S.Y., Yeo, H., Choi, I.G. 2018. Rapid prediction of the chemical information of wood powder from softwood species using near-infrared spectroscopy. BioResources 13(2): 2440-2451.

Schimleck, L.R., Evans, R. 2004. Estimation of Pinus radiata D. Don tracheid morphological characteristics by near infrared spectroscopy. Holzforschung 58(1): 66-73.

Schwanninger, M., Rodrigues, J.C., Fackler, K. 2011. A review of band assignments in near infrared spectra of wood and wood components. Journal of Near Infrared Spectroscopy 19(5): 287-308.

Sjostrom, E. 1993. Wood chemistry: fundamentals and applications. Gulf professional publishing.

Sluiter, A., Ruiz, R., Scarlata, C., Sluiter, J., Templeton, D. 2005. Determination of extractives in biomass. Laboratory Analytical Procedure (LAP). 1617.

Stark, N.M., Rowlands, R.E. 2007. Effects of wood fiber characteristics on mechanical properties of wood/polypropylene composites. Wood and Fiber Science 35(2): 167-174.

Tsuchikawa, S. 2007. A review of recent near infrared research for wood and paper. Applied Spectroscopy Reviews 42(1): 43-71.

Workman Jr, J., Weyer, L. 2007. Practical Guide to Interpretive Near-infrared Spectroscopy. CRC press.

Yang, S.Y., Park, Y., Chung, H., Kim, H., Park, S.Y., Choi, I.G., Kwon, O., Cho, K.C., Yeo, H. 2017. Partial least squares analysis on near-infrared absorbance spectra by air-dried specific gravity of major domestic softwood species. Journal of the Korean Wood Science and Technology 45(4): 399-408. 